\title{
Association of the GSTT1 polymorphism in upper aerodigestive tract cancer with tobacco smoking
}

\author{
T.M. Silva ${ }^{1,2}$, C.R. Marques $^{2}$, M.F. Marques Filho' ${ }^{2}$, A.B. Marques ${ }^{2}$, \\ G. Di Pietro ${ }^{3}$ and F. Rios-Santos ${ }^{4}$ \\ ${ }^{1}$ Departamento de Ciências Biológicas, \\ Universidade Estadual do Sudoeste da Bahia, Campus de Jequié, Jequié, BA, Brasil \\ ${ }^{2}$ Laboratório de Farmacogenômica e Epidemiologia Molecular, \\ Universidade Estadual de Santa Cruz, Ilhéus, BA, Brasil \\ ${ }^{3}$ Universidade Federal de Sergipe, Campus de Lagarto, Lagarto, SE, Brasil \\ ${ }^{4}$ Universidade Federal do Mato Grosso, Cuiabá, MT, Brasil
}

Corresponding author: T.M. Silva

E-mail: thiago@uesb.edu.br

Genet. Mol. Res. 13 (1): 528-537 (2014)

Received August 29, 2013

Accepted October 30, 2013

Published January 21, 2014

DOI http://dx.doi.org/10.4238/2014.January.21.22

\begin{abstract}
Polymorphisms in genes encoding xenobiotic-metabolizing enzymes might explain differences in the susceptibility to upper aerodigestive tract (UADT) cancers in individuals exposed to tobacco or other carcinogens. The present study aimed to evaluate the association of polymorphisms in the glutathione S-transferase (GST) candidate genes GSTM1, GSTT1, and GSTP1 with the risk of UADT cancers. GST gene polymorphisms were determined in 116 individuals with UADT cancer and 224 healthy controls using polymerase chain reaction-based methods. The GSTT1-null polymorphism was found to be a protective factor for UADT cancer [(odds ratio $(\mathrm{OR})=0.5,95 \%$ confidence interval $(C I)=0.27-0.93)]$, although this association was not confirmed when adjusted for gender, age, smoking, alcoholism, and self-reported skin color in the multivariate logistic regression model $(\mathrm{OR}=0.61,95 \% \mathrm{CI}$ $=0.29-1.28)$. The combined effect of GSTT1-positive genotypes with either the GSTP1 wild-type genotype (Ile/Ile) or the GSTP1 variant
\end{abstract}


genotypes (Ile/Val or $\mathrm{Val} / \mathrm{Val}$ ) increased the risk for UADT cancer $(\mathrm{OR}=4.34,95 \% \mathrm{CI}=1.06-17.78$ and $\mathrm{OR}=4.55,95 \% \mathrm{CI}=1.12-18.42$, respectively). A significant interaction was observed among moderate smokers carrying the GSTT1-positive genotype. In this population, the significant gene-gene and gene-environment interactions of GST polymorphisms may confer a substantial risk to UADT cancers.

Key words: Upper aerodigestive tract cancers; GST polymorphism; Smoking; Epidemiology

\section{INTRODUCTION}

Upper aerodigestive tract (UADT) cancers correspond to tumors on the oral cavity, larynx, and pharynx. These tumors represent the eighth most common cause of cancer-related deaths worldwide, accounting for $5 \%$ of all new cancers diagnosed (Choong and Vokes, 2008).

The main risk factors for this type of malignancy are smoking and alcohol consumption, which act both independently and synergistically in increasing the risk (Boffetta and Hashibe, 2006). Cigarette smoke contains dozens of carcinogens (Hoffmann et al., 1997), and alcohol, in addition to inducing direct DNA damage, acts mainly by facilitating the penetration of tobacco carcinogens into the mucosa of the UADT (Boffetta and Hashibe, 2006). However, although smoking is an important risk factor for cancer, only $20 \%$ of smokers develop UADT cancers (Hirvonen, 1995). Thus, host-related factors must play an important role in cancer susceptibility. Among these, polymorphisms in genes encoding xenobiotic metabolizing enzymes might explain differences in the susceptibility to UADT cancer in individuals exposed to tobacco or other carcinogens.

One of the most important detoxification systems is represented by enzymes of the glutathione S-transferase (GST) family, which catalyze the conjugation of glutathione with a variety of electrophilic compounds, including environmental carcinogens, cytotoxic drugs, and endogenous products derived from oxidative metabolism (Board et al., 2000). Four major polymorphic protein families of GSTs were identified in humans: $\alpha$ (GSTA) on chromosome 6, $\mu$ (GSTM) on chromosome 1, $\theta$ (GSTT) on chromosome 22, and $\pi(G S T P)$ on chromosome 11 (Strange et al., 2001). Regarding UADT cancers, GSTs may be of particular importance because they are expressed in the squamous mucosa of the UADT (Chen and Lin, 1997). In addition, they are responsible for the biotransformation of many xenobiotics contained in cigarette smoke, as benzo(a)pyrene, acrolein, and 4-aminobiphenyl (Olshan et al., 2000). Furthermore, a greater amount of micronuclei and DNA adducts were observed among smoker carriers of genotypes that confer a deficiency in GST activity (Lodovici et al., 2004; Palma et al., 2007).

Polymorphisms of complete deletion were described for the genes GSTT1 and GSTM1 (alleles GSTT1 null and GSTM1 null, respectively) resulting in a total loss of protein expression in homozygous individuals (Hayes et al., 2005). Three different alleles of GSTP1 were described: GSTP $1 * \mathrm{~A}$ (the wild-type allele), GSTP $1 * \mathrm{~B}$, and GSTP $1 * \mathrm{C}$. The variant GSTP1*B is a single nucleotide polymorphism (SNP) resulting from an $\mathrm{A} \rightarrow \mathrm{G}$ transition at nucleotide +313 of exon 5, changing codon 105 from ATC (Ile) to GTC (Val) (Board et al., 1990). Codon 105 comprises part of the active site of the enzyme for the binding of hydrophobic substrates (site $\mathrm{H}$ ), and the substitution Ile105 $\rightarrow$ Val at variant $G S T P 1 * B$ affects the substrate-specific catalytic activity and thermal stability of the encoded protein (Johansson et al., 1998). 
In this sense, it is reasonable to suppose that an interaction between different GST polymorphisms and environmental risk factors would modulate the susceptibility to the development of UADT cancers. Therefore, this study investigated the association between polymorphisms of the genes GSTM1, GSTT1, and GSTP1 and the risk of UADT cancers, as well as potential gene-gene and gene-environment interactions. In addition, this study represents the first report of the association between GST polymorphisms and risk of UADT cancers in a population of northeastern Brazil with a high degree of genetic admixture.

\section{MATERIAL AND METHODS}

\section{Subjects}

The cases (100 males and 16 females) were recruited at the High Complexity Oncology Center in the county of Itabuna and at the Oncology Clinic at Ilhéus, which are both located in the State of Bahia, Brazil, from February 2008 to August 2009. Healthy controls (193 men and 31 women), hospital-based $(\mathrm{N}=41)$ and from the general population $(\mathrm{N}=183)$, were recruited from the same region as the cases, and were matched for age, gender, and self-reported skin color. Demographic information on lifestyle and dietary habits were obtained from a socioeconomic questionnaire applied to both groups. Subjects who reported consuming at least one cigarette per day for a minimum period of one year were reported as smokers. Pack-years calculations were performed by multiplying the number of packs of cigarettes smoked per day by the total exposure time in years. According to this criterion, cases and controls were categorized as never smokers (pack-years $=0$ ), moderate smokers ( $\leq 20$ pack-years), and heavy smokers (pack-years $>20$ ). Regarding alcohol intake, individuals who reported drinking alcohol at a frequency of twice a week for more than a minimum of 1 year were considered drinkers. Approximately $3 \mathrm{~mL}$ peripheral blood was collected from each subject enrolled in the study for DNA extraction. The study was approved by the Ethics Committees of participating institutions.

\section{Genotyping of GSTM1 and GSTT1}

The genes GSTM1 and GSTT1 were amplified in a multiplex polymerase chain reaction (PCR) using the $\beta$-globin gene as an internal control of the reaction, as previously described (Gattas et al., 2006). The null genotypes for GSTT1 and GSTM1 were identified by the absence of amplification products of 480 and $215 \mathrm{bp}$, respectively.

\section{Genotyping of GSTP1 by PCR-restriction fragment length polymorphism (RFLP)}

PCR amplification and genotyping of the RFLP BsmaI of GSTP1 was performed as described previously (Leichsenring et al., 2006). The digestion products were electrophoresed on $3.0 \%$ agarose gel. The action of the enzyme BsmaI can generate three distinct digestion patterns: one band of $176 \mathrm{bp}$ covering the wild allele (Ile), two bands of 91 and $85 \mathrm{bp}$ for the mutant allele (Val), and three bands of 176, 91, and $85 \mathrm{bp}$ in the case of heterozygous individuals (Ile/Val).

\section{Statistical analysis}

To assess differences in genotypic and allelic frequencies between cases and controls, 
homogeneity tests using the $\chi^{2}$ statistic were performed. The Fisher exact test was applied for the same purpose when the expected value for a cell of the contingency table was less than 5. Odds ratios (ORs) with $95 \%$ confidence intervals (CI) were calculated to estimate the risk of UADT cancer associated with the different genetic and environmental factors evaluated. A conditional logistic regression model was applied to assess the risk of UADT cancer attributed to GST polymorphisms after adjusting for other variables of interest. The genotypic frequencies observed for the GSTP1 gene were tested for Hardy-Weinberg equilibrium (HWE) among cases and controls. Analysis of gene-environment interactions were conducted from stratified variables (genotype $\mathrm{x}$ smoking) that were introduced in logistic regression models with other selected variables. To test the significance of observed interactions, we applied a likelihood ratio test using the $\chi^{2}$ distribution. The Mann-Whitney U-test was applied to variables not normally distributed based on the Kolmogorov-Smirnov test. All statistical analyses were performed with the statistical package SPSS version 10.0 (SPSS; Chicago, IL, USA) adopting a significance level of $5 \%(\alpha=0.05)$.

\section{RESULTS}

The general characteristics of cases and controls are summarized in Table 1. There were no differences between groups in age, gender, and self-reported skin color. Alcohol intake resulted in a 4.21 -fold increased risk of developing UADT cancers $(95 \% \mathrm{CI}=2.52-7.05$, $\mathrm{P}<0.001)$. Tobacco smokers showed a 19.9 -fold increased risk of UADT cancers $(95 \% \mathrm{CI}=$ $8.39-47.18, \mathrm{P}<0.001)$. The combined analysis of exposure to smoking and alcohol consumption revealed an interaction between these factors in increasing the risk to UADT cancer (OR $=23.37,95 \% \mathrm{CI}=8.94-61.06, \mathrm{P}<0.001)$.

\begin{tabular}{|c|c|c|c|c|}
\hline Variable & Cases $(\mathrm{N}=116)$ & Controls $(\mathrm{N}=224)$ & OR $(95 \% \mathrm{CI})$ & $P$ value \\
\hline Gender [N (\%)] & & & - & - \\
\hline Male & $100(86.2)$ & $193(86.2)$ & & \\
\hline Female & $16(13.8)$ & $31(13.8)$ & & \\
\hline Males + female & 116 & 224 & & \\
\hline Age $($ mean $+\mathrm{SD})$ & $60.9 \pm 12.5$ & $58.2 \pm 11.9$ & - & $0.053^{*}$ \\
\hline \multicolumn{5}{|l|}{ Skin color [N (\%)] } \\
\hline Male & 100 & 193 & - & - \\
\hline White & $14(14.0)$ & $27(14.0)$ & & \\
\hline Non-white & $86(86.0)$ & $166(86.0)$ & & \\
\hline Female & 16 & 31 & - & - \\
\hline White & $3(18.8)$ & $6(19.4)$ & & \\
\hline Non-white & $13(81.2)$ & $25(80.6)$ & & \\
\hline \multicolumn{5}{|c|}{ Drinking status [N (\%)] } \\
\hline Never & $27(23.3)$ & $110(56.1)$ & 1 & \\
\hline Ever & $89(76.7)$ & 86 (43.9) & $4.21(2.52-7.05)$ & $<0.001$ \\
\hline \multicolumn{5}{|c|}{ Smoking status [N (\%)] } \\
\hline Never & $6(5.2)$ & $114(52.1)$ & 1 & \\
\hline Ever & $110(94.8)$ & $105(47.9)$ & $19.90(8.39-47.18)$ & $<0.001$ \\
\hline \multicolumn{5}{|c|}{ Smoking/drinking status [N (\%)] } \\
\hline Never/never & $5(4.3)$ & $81(41.3)$ & 1 & \\
\hline Ever/never & $22(19.0)$ & $29(14.8)$ & $12.29(4.26-35.46)$ & $<0.001$ \\
\hline Never/ever & $1(0.9)$ & $25(12.8)$ & $0.65(0.07-5.81)$ & 1 \\
\hline Ever/ever & $88(75.8)$ & $61(31.1)$ & $23.37(8.94-61.06)$ & $<0.001$ \\
\hline
\end{tabular}

$\mathrm{OR}=$ odds ratio $; 95 \% \mathrm{CI}=95 \%$ confidence interval. $*$ Student $t$-test. 
The genotype frequencies of GSTT1, GSTM1, and GSTP1 among cases and controls are described in Table 2. The frequency of the GSTM1-null genotype was higher among cases than among controls (44.8 vs 39.7\%, respectively), and there was no increased UADT cancer risk associated to this genotype $(\mathrm{OR}=1.23 ; 95 \% \mathrm{CI}=0.78-1.94, \mathrm{P}=0.366)$.

\begin{tabular}{|c|c|c|c|c|c|c|}
\hline Genotype & Cases N (\%) & Controls N (\%) & OR $(95 \% \mathrm{CI})$ & $\mathrm{P}$ value & $\mathrm{OR}^{\mathrm{a}}(95 \% \mathrm{CI})$ & P value \\
\hline \multicolumn{7}{|l|}{ GSTM1 } \\
\hline Positive & $64(55.2)$ & $135(60.3)$ & 1 & & & \\
\hline Null & $52(44.8)$ & $89(39.7)$ & $1.23(0.78-1.94)$ & 0.366 & $1.36(0.78-2.37)$ & 0.282 \\
\hline \multicolumn{7}{|l|}{ GSTT1 } \\
\hline Positive & $100(86.2)$ & $170(75.9)$ & 1 & & & \\
\hline Null & $16(13.8)$ & $54(24.1)$ & $0.50(0.27-0.93)$ & 0.026 & $0.61(0.29-1.28)$ & 0.193 \\
\hline \multicolumn{7}{|l|}{ GSTP1 } \\
\hline Ile/Ile & $49(42.2)$ & $102(47.0)$ & 1 & & & \\
\hline $\mathrm{Ile} / \mathrm{Val}$ & $51(44.0)$ & $94(43.3)$ & $1.13(0.70-1.82)$ & 0.621 & $1.2(0.50-2.81)$ & 0.695 \\
\hline $\mathrm{Val} / \mathrm{Val}$ & $16(13.8)$ & $21(9.7)$ & $1.58(0.76-3.30)$ & 0.216 & $0.93(0.39-2.20)$ & 0.875 \\
\hline $\mathrm{Ile} / \mathrm{Val}$ or $\mathrm{Val} / \mathrm{Val}$ & $67(57.8)$ & $115(53.0)$ & $1.21(0.77-1.90)$ & 0.405 & $1.25(0.71-2.20)$ & 0.431 \\
\hline Ile & $149(64.2)$ & $298(68.7)$ & 1 & & & \\
\hline Val & $83(35.8)$ & $136(31.3)$ & $1.22(0.87-1.70)$ & 0.245 & & \\
\hline
\end{tabular}

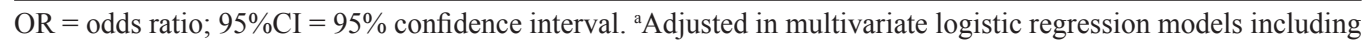
age, gender, skin color, smoking status, and consumption of alcohol. UADT $=$ upper aerodigestive tract.

The GSTT1 null frequency was higher among controls (24.1\%) compared to cases $(13.8 \%)$, resulting in a protective effect associated with this genotype $(\mathrm{OR}=0.50,95 \% \mathrm{CI}=$ $0.27-0.93, \mathrm{P}=0.026$ ). However, when adjusted for age, gender, skin color, smoking, and alcohol consumption, this association was no longer statistically significant (adjusted $\mathrm{OR}=0.61$, $95 \% \mathrm{CI}=0.29-1.28, \mathrm{P}=0.193$ ).

For the GSTP1 gene, the genotype frequencies did not differ between groups. Cases and controls did not differ for genotypes of GSTP1 when the dominant genetic model was adopted (non-adjusted $\mathrm{OR}=1.21,95 \% \mathrm{CI}=0.77-1.90, \mathrm{P}=0.405$ ). Genotype frequencies of GSTP1 were found to be in HWE in both cases and controls $(\mathrm{P}=0.997$ and $\mathrm{P}=1.0$, respectively) enabling the use of a multiplicative genetic model. In addition, in this case there were no significant differences for GSTP 1 allele frequencies between groups $(\mathrm{OR}=1.22,95 \% \mathrm{CI}=$ $0.87-1.70, \mathrm{P}=0.245$ ).

Gene-gene interaction analyses and its association with UADT cancer risk were also performed, and the results are shown in Table 3. Considering the combination of the GSTM1positive genotype with the GSTT1-null genotype as a reference group, we observed a more than 2-fold risk associated to the GSTM1-null and GSTT1-positive genotype combination (OR $=2.54 ; 95 \% \mathrm{CI}=1.06-6.05, \mathrm{P}=0.032)$. However, this difference was not statistically significant when adjusted using the multivariate logistic regression model $(\mathrm{OR}=2.45 ; 95 \% \mathrm{CI}=$ $0.88-6.79, \mathrm{P}=0.084)$.

Considering the GSTT1 null and GSTP1 Ile/Ile as a reference group, the combinations of GSTT1 positive with either variant GSTP1 (Ile/Val or Val/Val) or GSTP1 Ile/Ile were associated with a risk factor for UADT cancers $(\mathrm{OR}=4.54 ; 95 \% \mathrm{CI}=1.3-15.87, \mathrm{P}=0.011$ and $\mathrm{OR}=4.16,95 \% \mathrm{CI}=1.20-14.28, \mathrm{P}=0.017$, respectively). These results remained statistically significant when adjusted by the multivariate logistic regression model $(\mathrm{OR}=4.55,95 \% \mathrm{CI}=$ $1.12-18.42, \mathrm{P}=0.034$ and $\mathrm{OR}=4.34,95 \% \mathrm{CI}=1.06-17.78, \mathrm{P}=0.041$, respectively). 
Table 3. Combined effects of GSTM1, GSTT1 and GSTP1 genotypes in UADT cancer risk.

\begin{tabular}{|c|c|c|c|c|c|c|}
\hline Multilocus genotype & Cases $[\mathrm{N}(\%)]$ & Controls [N (\%)] & OR $(95 \% \mathrm{CI})$ & $P$ value & $\mathrm{OR}^{\mathrm{a}}(95 \% \mathrm{CI})$ & $P$ value \\
\hline \multicolumn{7}{|l|}{ GSTM1 and GSTT1 } \\
\hline Positive/null & $8(6.9)$ & $30(13.4)$ & 1 & & 1 & \\
\hline Null/positive & $44(37.9)$ & $65(29.0)$ & $2.54(1.06-6.05)$ & 0.032 & $2.45(0.88-6.79)$ & 0.084 \\
\hline Null/null & $8(6.9)$ & $24(10.7)$ & $1.25(0.41-3.81)$ & 0.695 & $1.60(0.42-6.11)$ & 0.490 \\
\hline Positive/positive & $56(48.3)$ & $105(46.9)$ & $2.00(0.86-4.76)$ & 0.103 & $1.81(0.67-4.85)$ & 0.237 \\
\hline \multicolumn{7}{|l|}{ GSTMI and GSTP1 } \\
\hline Positive and Ile/Ile & $30(25.9)$ & $69(31.8)$ & 1 & & 1 & \\
\hline Null and Ile/Ile & $19(16.4)$ & $33(15.2)$ & $1.32(0.65-2.70)$ & 0.437 & $1.29(0.55-3.05)$ & 0.557 \\
\hline Positive and Ile/Val or Val/Val & $34(29.3)$ & $61(28.1)$ & $1.28(0.70-2.33)$ & 0.417 & $1.18(0.58-2.42)$ & 0.640 \\
\hline Null and Ile/Val or Val/Val & $33(28.4)$ & $54(24.9)$ & $1.4(0.76-2.60)$ & 0.273 & $1.64(0.77-3.47)$ & 0.194 \\
\hline \multicolumn{7}{|l|}{ GSTT1 and GSTP1 } \\
\hline Null and Ile/Ile & $3(2.6)$ & $22(10.1)$ & 1 & & 1 & \\
\hline Positive and Ile/Val or $\mathrm{Val} / \mathrm{Val}$ & $54(46.6)$ & $87(40.1)$ & $4.54(1.13-15.87)$ & 0.011 & $4.55(1.12-18.42)$ & 0.034 \\
\hline Null and Ile/Val or Val/Val & $13(11.2)$ & $28(12.9)$ & $3.40(0.86-13.15)$ & 0.07 & $4.50(0.94-21.61)$ & 0.060 \\
\hline Positive and Ile/Ile & $46(39.7)$ & $80(36.9)$ & $4.16(1.20-14.28)$ & 0.017 & $4.34(1.06-17.78)$ & 0.041 \\
\hline
\end{tabular}

$\mathrm{OR}=$ odds ratio $; 95 \% \mathrm{CI}=95 \%$ confidence interval. ${ }^{\text {a Adjusted } \mathrm{OR} \text { in multivariate logistic regression models }}$ including age, gender, skin color, smoking status, and consumption of alcohol. UADT $=$ upper aerodigestive tract.

The results of the interaction analysis between smoking and different GST genotypes are shown in Table 4. The interaction between the GSTM1 null genotype and smoking resulted in an increased UADT cancer risk among moderate and heavy smokers. However, these interactions were not significant according to the likelihood ratio test $(\mathrm{P}=0.078$ and $\mathrm{P}=0.390$, respectively). We observed a significant interaction between GSTT1 and moderate smoking $(\leq 20$ pack-years). For carriers of the GSTT1-null genotype, the OR was $2.4(95 \% \mathrm{CI}=0.38-14.81)$, whereas for those with the GSTT1-positive genotype, the OR was $13.28(95 \% \mathrm{CI}=4.03-41.0)$. This difference was statistically significant based on the likelihood ratio test $(\mathrm{P}=0.012)$. There was no significant interaction between the GSTP1 gene and tobacco use.

Table 4. Distribution of GST genotypes on the basis of tobacco consumption among upper aerodigestive tract (UADT) cancer patients and controls.

\begin{tabular}{|c|c|c|c|c|c|c|c|c|}
\hline \multirow[t]{2}{*}{ Pack-years } & \multicolumn{4}{|c|}{ GSTM1 positive } & \multicolumn{4}{|c|}{ GSTM1 null } \\
\hline & Cases & Controls & $\mathrm{OR}^{\mathrm{a}}(95 \% \mathrm{CI})$ & $\mathrm{P}$ & Cases & Controls & $\mathrm{OR}^{\mathrm{a}}(95 \% \mathrm{CI})$ & $\mathrm{P}$ \\
\hline 0 & $4(4.2)$ & $69(34.2)$ & 1 & - & $2(2.1)$ & $45(22.3)$ & $0.81(0.14-4.72)$ & 0.817 \\
\hline$\leq 20$ & $16(16.8)$ & $32(15.8)$ & $7.86(2.25-27.52)$ & 0.001 & $18(18.9)$ & $22(10.9)$ & $16.41(4.46-60.40)$ & $<0.001$ \\
\hline \multirow[t]{3}{*}{$>20$} & $31(32.6)$ & $22(10.9)$ & $19.35(5.53-67.71)$ & $<0.001$ & $24(25.3)$ & $12(5.9)$ & $29.86(7.85-113.60)$ & $<0.001$ \\
\hline & \multicolumn{4}{|c|}{ GSTT1 positive } & \multicolumn{4}{|c|}{ GSTT1 null } \\
\hline & Cases & Controls & $\mathrm{OR}^{\mathrm{a}}(95 \% \mathrm{CI})$ & $\mathrm{P}$ & Cases & Controls & $\mathrm{OR}^{\mathrm{a}}(95 \% \mathrm{CI})$ & $\mathrm{P}$ \\
\hline 0 & $5(5.3)$ & $84(41.6)$ & 1 & - & $1(1.1)$ & $30(14.9)$ & $0.62(0.07-5.66)$ & 0.674 \\
\hline$\leq 20$ & $32(33.7)$ & $41(20.3)$ & $13.28(4.30-41.0)$ & $<0.001$ & $2(2.1)$ & $13(6.4)$ & $2.40(0.38-14.81)$ & 0.349 \\
\hline \multirow[t]{3}{*}{$>20$} & $46(48.4)$ & $29(14.4)$ & $22.16(7.07-69.42)$ & $<0.001$ & $9(9.5)$ & $5(2.5)$ & $22.55(4.78-106.31)$ & $<0.001$ \\
\hline & \multicolumn{4}{|c|}{ GSTP1 Ile/Ile } & \multicolumn{4}{|c|}{ GSTP1 Ile/Val or Val/Val } \\
\hline & Cases & Controls & $\mathrm{OR}^{\mathrm{a}}(95 \% \mathrm{CI})$ & $\mathrm{P}$ & Cases & Controls & $\mathrm{OR}^{\mathrm{a}}(95 \% \mathrm{CI})$ & $\mathrm{P}$ \\
\hline 0 & $2(2.1)$ & $52(26.5)$ & 1 & - & $4(4.2)$ & $59(30.1)$ & $1.19(0.33-11.04)$ & 0.47 \\
\hline$\leq 20$ & $19(20.0)$ & $26(13.3)$ & $17.11(3.45-84.86)$ & 0.001 & $15(15.8)$ & $26(13.3)$ & $16.67(3.28-84.61)$ & 0.001 \\
\hline$>20$ & $20(21.1)$ & $13(6.6)$ & $31.04(5.95-161.90)$ & $<0.001$ & $35(36.8)$ & $20(10.2)$ & $38.91(7.81-193.90)$ & $<0.001$ \\
\hline
\end{tabular}

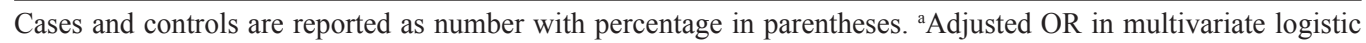
regression models including age, gender, skin color, smoking status, and consumption of alcohol. 


\section{DISCUSSION}

The population frequencies of some polymorphisms of GSTs show variations among different ethnic groups. The frequency of the GSTM1-null genotype, for instance, varies from 42 to $60 \%$ among Caucasians and from 16 to $36 \%$ among Africans (Garte et al., 2001). Interestingly, some studies have shown a relationship between cancer incidence and ethnicity (Brawley, 2003). In the North American population, for example, there is a higher incidence and mortality rate of UADT cancers among African-Americans compared to Euro-Americans (Shavers et al., 2003). These differences may be related to different genetic backgrounds between these ethnic groups, including different distributions of polymorphisms in the genes involved in the metabolism of xenobiotics. In this sense, the study of polymorphisms in these candidate genes is an interesting approach to providing better insight in regards to interpopulation and interindividual differences in the susceptibility to malignancies.

Although the GSTM1-null genotype has been shown to be a significant risk factor to different types of cancers, including lung (Lee et al., 2006), esophagus (Lu et al., 2005), and bladder (Yuan et al., 2008) cancers, this study found no association between this polymorphism and UADT cancer, in agreement with observations in other Brazilian populations (Biselli et al., 2006; Hatagima et al., 2008) and global populations (Olshan et al., 2000; Boccia et al., 2008). These results, however, do not corroborate with previous data obtained from other Brazilian populations (Drummond et al., 2004; Gattas et al., 2006). These differences may be due to the smaller sample size of these studies, as well as the criteria used in the recruitment of controls (hospital-based only). Importantly, different types of biases can be introduced into the analysis based on hospital controls, which generally makes this type of comparison group undesirable (Grimes and Schulz, 2002).

Although the GSTT1-null genotype has been associated with a risk factor for UADT cancer in previous studies (Soya et al., 2007; Singh et al., 2008), in this study, this polymorphism was significantly associated with a protective factor for this malignancy, in agreement with some other studies (Oude Ophuis et al., 2006; Anantharaman et al., 2007); however, this association was not confirmed when adjusted for other variables. A possible explanation for these results is the dual role of GST $\theta$, which may catalyze both the bioactivation and the detoxification of xenobiotics (Landi, 2000). An important example is the conversion of methyl chloride into S-chloromethyl glutathione, which, after hydrolysis, becomes formaldehyde, a known carcinogen to humans and animals (Sherratt et al., 1998). Although methyl chloride is not associated with cigarette smoke, it is likely that it contains other compounds capable of generating carcinogenic agents after suffering bioactivation mediated by GSTT1 (Evans et al., 2004). Additionally, it was shown that workers with the GSTT1-null genotype exposed to polycyclic aromatic hydrocarbons had lower concentration of 8-oxoguanine, the main biomarker of oxidative DNA damage (Garte et al., 2007). Thus, the role of this polymorphism in UADT cancer risk could be subject to the relative exposure levels to carcinogens that are detoxified or bioactivated through these enzymes.

We observed no association between the GSTP1 Ile105Val polymorphism and UADT cancer risk. Corroborating our data, few studies have associated the GSTP $1 * B$ variant with UADT cancer risk (Lazarus and Park, 2000; Hashibe et al., 2003). Furthermore, our results are in accordance with those reported by other authors for the GSTP1 Ile105Val polymorphism and oral cancer risk in Brazilian populations (Leichsenring et al., 2006; Hatagima et al., 2008). 
Since GST enzymes share some substrates, we can consider them, at least in part, as a functionally redundant system (Hayes et al., 2005). These different candidate loci would therefore be more informative when evaluated within a multigenic disease model. For this reason, we conducted an analysis of gene-gene interactions by combining the different genotypes of GSTM1, GSTT1, and GSTP1.

In the analysis of interactions between GSTM1 and GSTT1, we found that the highrisk genotype combination (GSTM1 null and GSTT1 positive) significantly increased the risk of UADT cancers compared to the reference group (GSTM1 positive and GSTT1 null). In addition, the GSTT1-positive allele did not confer a significantly increased risk in individuals that simultaneously carried at least one functional copy of GSTM1. Although these results were not statistically significant when adjusted with the logistic regression model, it nonetheless suggested the existence of an interaction between these loci in the modulation of the susceptibility to UADT cancers. A possible explanation is that specific pre-carcinogens that are present in cigarette smoke may be bioactivated by GSTT1 and detoxified by the GSTM1 pathways.

In the analysis involving GSTT1 and GSTP1, individuals with the GSTT1-positive genotype had an increased risk relative to the reference group (GSTT1 null and GSTP1 Ile/ Ile) regardless of the GSTP1 alleles that they co-carried. This result suggests the independent role of the GSTT1-positive genotype in increasing the risk of UADT cancers when compared together with the effect of GSTP1. Finally, we found no combination of risk or protection in the grouped analysis of GSTM1 and GSTP1 genes.

The interaction of the GSTM1-null genotype with smoking did not result in a significant increase of UADT cancers for moderate or heavy smokers. Soya et al. (2007) observed an interaction between this genotype and tobacco use in UADT cancer for tobacco-chewers, but not for tobacco smokers. Moreover, this lack of interaction between the GSTM1-null genotype and tobacco smoking in UADT cancer was also previously reported (Olshan et al., 2000).

Although the influence of the GSTP1 Ile105Val polymorphism on the UADT cancer risk has been reported both for heavy (Soya et al., 2007) and moderate (Park et al., 1999) smokers, this study did not detect any significant interaction of this polymorphism with tobacco smoking. This result is in agreement with results of previous studies (Singh et al., 2008).

The GSTT1-null genotype conferred a decreased UADT cancer risk for moderate smokers. However, for heavy smokers, this genotype was not a significant risk modifier. This finding is consistent with the assumption that polymorphisms in genes of xenobiotic metabolism would be most important for cancer susceptibility in response to lower levels of exposure to carcinogens (Vineis and Martone, 1995). Furthermore, in agreement with our results, a study conducted in India demonstrated the protective role of the GSTT1-null allele in oral cancer among patients who consumed tobacco (Anantharaman et al., 2007).

An important limitation of the present study is the small sample size, which leads to a considerable lack of statistical power. Thus, it is possible that our results may be due to chance, as several gene-gene and gene-environment interactions were examined. Therefore, these findings should be interpreted with caution and need be confirmed in larger, well-designed studies.

In conclusion, this study showed that the GSTT1-null genotype was a protective factor for the development of UADT cancers in the study population, especially among moderate smokers. Analyses of gene-gene interactions revealed the existence of genotype combinations between GST loci that were significantly associated with risk or protective factors for this ma- 
lignancy. Thus, these genotypes would be more informative and important for the exploration of population groups that are genetically more susceptible to UADT cancers when considered within a multigenic disease model.

\section{ACKNOWLEDGMENTS}

Research supported by grants from the National Council for Research Brazil (Conselho Nacional de Pesquisa - CNPq) and the Foundation for Research Support of the Bahia State (Fundação de Amparo à Pesquisa do Estado da Bahia - FAPESB). We also thank Dr. Liane Rossi Ferreira and Dr. Ari Paranhos for helping throughout the study.

\section{Conflicts of interest}

The authors declare no conflict of interest.

\section{REFERENCES}

Anantharaman D, Chaubal PM, Kannan S, Bhisey RA, et al. (2007). Susceptibility to oral cancer by genetic polymorphisms at CYP1A1, GSTM1 and GSTT1 loci among Indians: tobacco exposure as a risk modulator. Carcinogenesis 28: $1455-1462$.

Biselli JM, de Angelo Calsaverini Leal RC, Ruiz MT, Goloni-Bertollo EM, et al. (2006). GSTT1 and GSTM1 polymorphism in cigarette smokers with head and neck squamous cell carcinoma. Braz. J. Otorhinolaryngol. 72: 654-658.

Board P, Coggan M, Johnston P, Ross V, et al. (1990). Genetic heterogeneity of the human glutathione transferases: a complex of gene families. Pharmacol. Ther. 48: 357-369.

Board PG, Coggan M, Chelvanayagam G, Easteal S, et al. (2000). Identification, characterization, and crystal structure of the Omega class glutathione transferases. J. Biol. Chem. 275: 24798-24806.

Boccia S, Cadoni G, Sayed-Tabatabaei FA, Volante M, et al. (2008). CYP1A1, CYP2E1, GSTM1, GSTT1, EPHX1 exons 3 and 4, and NAT2 polymorphisms, smoking, consumption of alcohol and fruit and vegetables and risk of head and neck cancer. J. Cancer Res. Clin. Oncol. 134: 93-100.

Boffetta P and Hashibe M (2006). Alcohol and cancer. Lancet Oncol. 7: 149-156.

Brawley OW (2003). Population categorization and cancer statistics. Cancer Metastasis Rev 22: 11-19.

Chen YK and Lin LM (1997). Evaluation of glutathione S-transferase activity in human buccal epithelial dysplasias and squamous cell carcinomas. Int. J. Oral Maxillofac. Surg. 26: 205-209.

Choong $\mathrm{N}$ and Vokes E (2008). Expanding role of the medical oncologist in the management of head and neck cancer. $C A$ Cancer J. Clin. 58: 32-53.

Drummond SN, De Marco L, Noronha JC and Gomez RS (2004). GSTM1 polymorphism and oral squamous cell carcinoma. Oral Oncol. 40: 52-55.

Evans AJ, Henner WD, Eilers KM, Montalto MA, et al. (2004). Polymorphisms of GSTT1 and related genes in head and neck cancer risk. Head Neck 26: 63-70.

Garte S, Gaspari L, Alexandrie AK, Ambrosone C, et al. (2001). Metabolic gene polymorphism frequencies in control populations. Cancer Epidemiol. Biomarkers Prev. 10: 1239-1248.

Garte S, Taioli E, Popov T, Kalina I, et al. (2007). Role of GSTT1 deletion in DNA oxidative damage by exposure to polycyclic aromatic hydrocarbons in humans. Int. J. Cancer 120: 2499-2503.

Gattas GJ, de Carvalho MB, Siraque MS, Curioni OA, et al. (2006). Genetic polymorphisms of CYP1A1, CYP2E1, GSTM1, and GSTT1 associated with head and neck cancer. Head Neck 28: 819-826.

Grimes DA and Schulz KF (2002). Bias and causal associations in observational research. Lancet 359: 248-252.

Hashibe M, Brennan P, Strange RC, Bhisey R, et al. (2003). Meta- and pooled analyses of GSTM1, GSTT1, GSTP1, and CYP1A1 genotypes and risk of head and neck cancer. Cancer Epidemiol. Biomarkers Prev. 12: 1509-1517.

Hatagima A, Costa EC, Marques CF, Koifman RJ, et al. (2008). Glutathione S-transferase polymorphisms and oral cancer: a case-control study in Rio de Janeiro, Brazil. Oral Oncol. 44: 200-207.

Hayes JD, Flanagan JU and Jowsey IR (2005). Glutathione transferases. Annu. Rev. Pharmacol. Toxicol. 45: 51-88.

Hirvonen A (1995). Genetic factors in individual responses to environmental exposures. J. Occup. Environ. Med. 37: 37-43. 
Hoffmann D, Djordjevic MV and Hoffmann I (1997). The changing cigarette. Prev. Med. 26: 427-434.

Johansson AS, Stenberg G, Widersten M and Mannervik B (1998). Structure-activity relationships and thermal stability of human glutathione transferase P1-1 governed by the H-site residue 105. J. Mol. Biol. 278: 687-698.

Landi S (2000). Mammalian class theta GST and differential susceptibility to carcinogens: a review. Mutat. Res. 463: 247-283.

Lazarus P and Park JY (2000). Metabolizing enzyme genotype and risk for upper aerodigestive tract cancer. Oral Oncol. 36: 421-431.

Lee KM, Kang D, Lee SJ, Park SK, et al. (2006). Interactive effect of genetic polymorphism of glutathione S-transferase M1 and smoking on squamous cell lung cancer risk in Korea. Oncol. Rep. 16: 1035-1039.

Leichsenring A, Losi-Guembarovski R, Maciel ME, Losi-Guembarovski A, et al. (2006). CYP1A1 and GSTP1 polymorphisms in an oral cancer case-control study. Braz. J. Med. Biol. Res. 39: 1569-1574.

Lodovici M, Luceri C, Guglielmi F, Bacci C, et al. (2004). Benzo(a)pyrene diolepoxide (BPDE)-DNA adduct levels in leukocytes of smokers in relation to polymorphism of CYP1A1, GSTM1, GSTP1, GSTT1, and mEH. Cancer Epidemiol. Biomarkers Prev. 13: 1342-1348.

Lu XM, Zhang YM, Lin RY, Arzi G, et al. (2005). Relationship between genetic polymorphisms of metabolizing enzymes CYP2E1, GSTM1 and Kazakh's esophageal squamous cell cancer in Xinjiang, China. World J. Gastroenterol. 11: 3651-3654.

Olshan AF, Weissler MC, Watson MA and Bell DA (2000). GSTM1, GSTT1, GSTP1, CYP1A1, and NAT1 polymorphisms, tobacco use, and the risk of head and neck cancer. Cancer Epidemiol. Biomarkers Prev. 9: 185-191.

Oude Ophuis MB, Manni JJ and Peters WH (2006). Glutathione S-transferase T1 null polymorphism and the risk for head and neck cancer. Acta Otolaryngol. 126: 311-317.

Palma S, Cornetta T, Padua L, Cozzi R, et al. (2007). Influence of glutathione S-transferase polymorphisms on genotoxic effects induced by tobacco smoke. Mutat. Res. 633: 1-12.

Park JY, Schantz SP, Stern JC, Kaur T, et al. (1999). Association between glutathione S-transferase pi genetic polymorphisms and oral cancer risk. Pharmacogenetics 9: 497-504.

Shavers VL, Harlan LC, Winn D and Davis WW (2003). Racial/ethnic patterns of care for cancers of the oral cavity, pharynx, larynx, sinuses, and salivary glands. Cancer Metastasis Rev. 22: 25-38.

Sherratt PJ, Manson MM, Thomson AM, Hissink EA, et al. (1998). Increased bioactivation of dihaloalkanes in rat liver due to induction of class theta glutathione S-transferase T1-1. Biochem. J. 335 (Pt 3): 619-630.

Singh M, Shah PP, Singh AP, Ruwali M, et al. (2008). Association of genetic polymorphisms in glutathione S-transferases and susceptibility to head and neck cancer. Mutat. Res. 638: 184-194.

Soya SS, Vinod T, Reddy KS, Gopalakrishnan S, et al. (2007). Genetic polymorphisms of glutathione-S-transferase genes (GSTM1, GSTT1 and GSTP1) and upper aerodigestive tract cancer risk among smokers, tobacco chewers and alcoholics in an Indian population. Eur. J. Cancer 43: 2698-2706.

Strange RC, Spiteri MA, Ramachandran S and Fryer AA (2001). Glutathione-S-transferase family of enzymes. Mutat. Res. 482: 21-26.

Vineis P and Martone T (1995). Genetic-environmental interactions and low-level exposure to carcinogens. Epidemiology 6: $455-457$.

Yuan JM, Chan KK, Coetzee GA, Castelao JE, et al. (2008). Genetic determinants in the metabolism of bladder carcinogens in relation to risk of bladder cancer. Carcinogenesis 29: 1386-1393. 